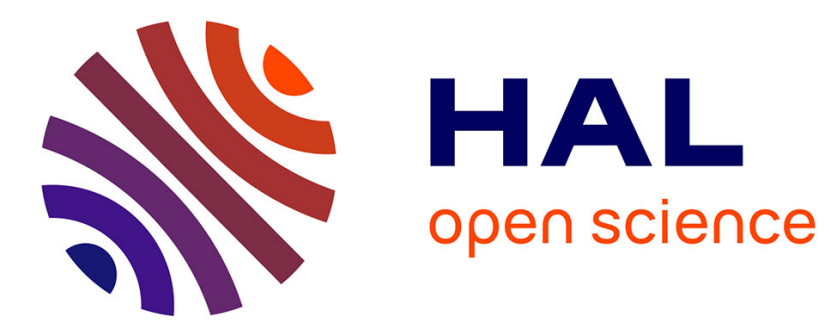

\title{
Les Petits romantiques et le rococo: éloge du mauvais goût
}

Catherine Thomas-Ripault

\section{To cite this version:}

Catherine Thomas-Ripault. Les Petits romantiques et le rococo: éloge du mauvais goût. Romantisme: la revue du dix-neuvième siècle, 2004, 123, pp.21-39. halshs-01271896

\section{HAL Id: halshs-01271896 \\ https://shs.hal.science/halshs-01271896}

Submitted on 1 Jul 2019

HAL is a multi-disciplinary open access archive for the deposit and dissemination of scientific research documents, whether they are published or not. The documents may come from teaching and research institutions in France or abroad, or from public or private research centers.
L'archive ouverte pluridisciplinaire HAL, est destinée au dépôt et à la diffusion de documents scientifiques de niveau recherche, publiés ou non, émanant des établissements d'enseignement et de recherche français ou étrangers, des laboratoires publics ou privés. 


\title{
Les Petits romantiques et le rococo : éloge du mauvais goût
}

Catherine Thomas-Ripault

\begin{abstract}
Un style nouveau est apparu en Europe vers 1700, dont plus personne ne conteste l'originalité ; il s'est développé en France dans les dernières années du règne de Louis XIV et s'est révélé au grand jour sous la Régence ; il a connu son apogée au temps de la marquise de Pompadour; il a cédé, après 1760, à la montée du néo-classicisme, du réalisme sentimental et révolutionnaire. Il a eu ses maîtres dans tous les domaines: Oppenord, Vassé, Meissonnier et Lajoue, Watteau, Lancret et Boucher, de Cotte, Boffrand et J.-A. Gabriel, Marivaux et Crébillon, bien d'autres encore. Ce style, qui n'est ni baroque, ni classique, on s'accorde aujourd'hui à le nommer rococo, non sans réticences d'ailleurs. ${ }^{1}$
\end{abstract}

Ces réticences relevées en 1970 par Jean Sgard autour du terme rococo, nous les retrouvons plus vives encore tout au long du XIX $\mathrm{X}^{\mathrm{e}}$ siècle. Rococo, comme Pompadour, dont le sens est très proche, sont fortement entachés de connotations négatives dont ils ne se déferont jamais tout à fait. Cependant, sous la monarchie de Juillet, l'art du XVIII ${ }^{\mathrm{e}}$ siècle toujours majoritairement dédaigné suscite certains commentaires qui laissent entrevoir un changement à la fois dans le regard que les " Petits romantiques " portent sur le passé, et dans l'évolution de leur propre esthétique. Nous tenterons de comprendre ce changement, en saisissant ce qui, dans la nature même de la branche ultime du romantisme, dans l'attitude et les préceptes littéraires des cadets de ces grands mages qui avaient lancé le mouvement, présente des affinités avec les principes esthétiques du passé, et permet d'appréhender les manifestations de sympathie qu'ils ont pu soudain susciter.

Lorsqu'en 1842, le mot est défini pour la première fois dans le supplément au dictionnaire de l'Académie Française, il est très nettement empreint de nuances péjoratives, et se voit classer dans le registre familier. Employé dans un sens figuré, il désigne toute vieillerie désuète et un peu ridicule :

Rococo se dit trivialement du genre d'ornement, de style et de dessin qui appartient à l'école du règne de Louis XV et du commencement de Louis XVI. Le genre rococo a suivi et précédé le Pompadour, qui n'est de même qu'une nuance du rococo. (...) il se dit en général de tout ce qui est vieux et hors de mode dans les arts, la littérature, le costume, les manières etc. ${ }^{2}$

Cette introduction tardive dans la langue, bien postérieure à l'émergence du style qu'il dénote - au XVIII ${ }^{\mathrm{e}}$ siècle, le style rococo est appelé le style moderne, ou le genre pittoresque ${ }^{3}$ - rend ce terme particulièrement intéressant, puisque qu'il se fait le reflet, à travers le XIX ${ }^{\mathrm{e}}$, de l'évolution du regard que posent les romantiques sur l'art du passé. La coexistence, dès l'apparition officielle du mot dans la langue, d'un sens propre, et d'un sens figuré péjoratif, est révélatrice de la piètre place qu'occupait l'esthétique rococo dans le goût des écrivains : elle est, d'emblée, considérée comme un art vieillot et radicalement dépassé. Le sens que prend, dans les années 1830, le terme Pompadour, utilisé dès le XVIII ${ }^{\mathrm{e}}$ siècle

\footnotetext{
${ }^{1}$ J. Sgard, «style rococo et style régence », La Régence, Centre aixois d'études et de recherches sur le dixhuitième siècle, Paris, Colin, 1970, p. 11.

${ }^{2}$ Cité par F. Kimball, Le Style Louis XV. Origine et évolution du rococo, Paris, Ed. A. et J. Picard et C ${ }^{\mathrm{ie}}, 1949$, p. 11.

${ }^{3}$ Voir F. Kimball, Ibid., p. 9.
} 
pour désigner l'art en vogue sous Louis $\mathrm{XV}$, ne fait que confirmer ce mépris affiché à l'égard du rococo sous la monarchie de Juillet : d'abord neutre, le terme désigne, comme adjectif, un «style maniéré à la mode sous Louis XV que l'on imprima à des objets ou à des meubles »; c'est à partir de 1833 qu'il prend un sens fortement péjoratif : il est alors signalé comme synonyme de rococo, et signifie « suranné, passé de mode » ${ }^{4}$.

L'acception péjorative du terme rococo date de ses tout premiers emplois : Delecluze mentionne la première occurrence du mot, à la fin du XVIII ${ }^{\mathrm{e}}$ siècle, comme appartenant au registre argotique ${ }^{5}$. Un article paru en 1835 dans la revue L'Artiste semble confirmer ces dires : l'auteur situe la naissance de ce terme dans les milieux artistiques au tout début du $\mathrm{XIX}^{\mathrm{e}}$ siècle, où rococo vient traduire le sentiment de profond mépris ressenti, à cette époque, par la jeune génération pour tout ce qui touche au passé :

On se rappelle quelle aversion nous avons eue, tous tant que nous sommes de la génération présente, pour ce qui retraçait à nos yeux les mœurs et les usages de la génération qui finit avec la révolution de 89 . Ce fut pour notre première jeunesse l'objet d'inépuisables railleries; les épithètes les plus ridicules ne nous suffisaient pas, et ce fut à ce propos que nous inventâmes tout exprès dans les ateliers l'expression de rococo. Alors personne n'eût osé dire, bien plus, personne n'eût osé penser qu'il y eut quelque charme dans l'habillement, dans la tournure de ces gens de l'autre siècle que nous revoyons en peinture. Leurs allégories excitaient encore plus nos rires et presque notre colère, et dans notre ardeur de réaction et de destruction contre tout ce qui nous tombait de rococo sous le regard, meubles, tableaux, sculpture, architecture, nous aurions pu prendre la devise des philosophes de ce temps tant ridiculisé : «Ecrasons l'infâme ». ${ }^{6}$

Le rejet de l'esthétique du XVIII ${ }^{\mathrm{e}}$ siècle au seuil du XIX ${ }^{\mathrm{e}}$ est ici très clairement exprimé, et présenté comme un sentiment général, commun à toute une génération. En 1829, l'emploi de ce terme par Stendhal indique qu'il appartient toujours, à cette époque, au même registre argotique : "me permettra-t-on un mot bas ? Le Bernin fut le père de ce mauvais goût désigné dans les ateliers sous le nom un peu vulgaire de rococo $»^{7}$, écrit-il dans ses Promenades dans Rome.

Tout au long des années 1830-1850, nous trouvons encore de fréquents emplois péjoratifs de rococo. Pris dans un sens figuré, le terme reste profondément dépréciatif. En 1834, Félix Pyat, dans le Nouveau tableau de Paris au dix-neuvième siècle, le fait figurer dans le répertoire d'insultes propre au langage des Jeunes-France, aux côtés de "bourgeois", "pair de France", "perruque", ou encore "comme il faut" ${ }^{8}$. L'emploi de ce terme dans les ouvrages de l'époque vérifie ce classement: l'un des personnages des Jeunes-France de Gautier, évoquant une pièce classique qui lui semble d'une ridicule désuétude, rend un verdict plein de mépris : «c'est empire, c'est perruque, c'est rococo, c'est pompadour » ${ }^{9}$. De même dans $L e$ Cousin Pons, le héros de Balzac s'exclame: «Mais vous ne savez pas que si je tarde seulement quinze jours à ma convalescence, on me dira, quand je reviendrai, que je suis

\footnotetext{
${ }^{4}$ Trésor de la Langue Française, t. XIV, Paris, Ed. du CNRS, 1988, p. 750.

5 «Ces expressions : Pompadour, rococo, à peu près admises aujourd'hui dans la conversation, pour désigner le goût à la mode pendant le règne de Louis XV, ont été employées pour la première fois par Maurice Quaï en 1796-97. Alors ces locutions (on pourrait dire cet argot) n'étaient usitées et comprises que dans les ateliers de peintres » (E. J. Delécluze, Louis David, son école et son temps (1855), n. 82, cité par F. Kimball, op. cit., p. 10). ${ }^{6}$ Anonyme, «La Poupée. Petit, Petit, dessins par Gavarni », L'Artiste, 1835, $1^{\text {ère }}$ série, X, p. 37.

725 mars 1829, Promenades dans Rome (1829), Voyages en Italie, textes établis, présentés et annotés par V. Del Litto, Paris, Gallimard, «Bibliothèque de la Pléiade », 1973, p. 782.

${ }^{8}$ « La plus grande injure qu'ils puissent s'appliquer, est de s'appeler rococo, pair de France, empire, perruque, comme il faut, académie, académie ! dernier degré du bourgeois ! » (F. Pyat, «Les Artistes », Nouveau tableau de Paris au XIX siècle, Paris, Charles-Béchet, 1834, t. IV, p. 9).

${ }^{9}$ Daniel Jobard (1833), Les Jeunes France, Romans, contes et nouvelles, Paris, Gallimard, « Bibliothèque de la Pléiade », 2002, p. 73.
} 
perruque, un vieux, que mon temps est fini, que je suis Empire, rococo ! ${ }^{10}$. Le contexte sémantique ne permet pas d'en douter: de manière générale, rococo prend bien dans la littérature de cette époque le sens figuré que lui attribuent les dictionnaires, de "vieillot" ou de "suranné", en insistant sur tout ce que ces deux adjectifs peuvent signifier de ridicule ou de risible. Le terme peut également s'appliquer à quelque chose que l'on juge excessivement conventionnel, significatif d'un esprit étroit à force d'être bien-pensant. C'est le sens qu'il prend dans cette exclamation d'un personnage des Jeunes-France de Théophile Gautier, étonné de trouver des marques de résistance chez sa servante habituellement favorable à ses avances :

- Sais-tu, Mariette, que tu deviens monstrueusement vertueuse! Si cela continue, on te pourra mettre au calendrier comme vierge et martyre. C'est pourtant quelque chose de bien ignoble et de bien rococo que la vertu, et je ne comprends pas à propos de quoi tu t'avises d'en avoir, étant passablement jolie et n'ayant guère que vingt ans. ${ }^{11}$

Un passage extrait d'un ouvrage appartenant à la littérature populaire, Les Mystères de Paris d'Eugène Sue, vient confirmer ce sens : «je sais qu'il n'y a rien de plus rococo, de plus perruque, que la fidélité. Mais c'est un faible que j'ai comme ça $»^{12}$, déclare un personnage. Vertu et fidélité sont ainsi qualifiées de "rococo" par des personnages qui se veulent libres d'esprit et de mœurs : l'adjectif est alors presque synonyme de "rétrograde". De tout évidence, le rococo, prenant le sens général de "dépassé", "vieux jeu", n’est pas pris au sérieux, et se voit l'objet de multiples moqueries.

Parfois, sens figuré et sens propres se mêlent dans le même rejet : dans La Peau de chagrin, le narrateur, forcé par ses créanciers de vendre le mobilier hérité de son père, ensemble d'objets de luxe qui ont entouré son enfance et auxquels il accordait une grande valeur, est tout surpris de constater le peu d'argent qu'il obtient en retour :

«Oh! me dit le commissaire-priseur, tout cela était bien rococo!» Mot épouvantable, qui flétrissait toutes les religions de mon enfance et me dépouillait de mes premières illusions, les plus chères de toutes. ${ }^{13}$

Ici, rococo désigne l'art du XVIII ${ }^{\mathrm{e}}$ siècle - il est probable que le mobilier relevait du style en vogue à l'époque du père du héros - et prend en même temps le sens figuré de "vieux jeu". Notons que l'intrigue du roman se déroule en 1826 ; mais la narration date de 18301831 , et il y a tout lieu de penser que le terme, à cette époque, garde sa valeur négative et ses connotations ridicules. En 1857, Flaubert, commentant la rédaction de Salammbô, attribue encore à l'adjectif, cette fois appliqué à la littérature, toute sa charge dépréciative : «quel chien de sujet ! je passe alternativement de l'emphase la plus extravagante à la platitude la plus académique. Cela sent tour à tour le Petrus Borel et le Jacques Delille. Parole d'honneur ! j'ai peur que ce ne soit poncif et rococo en diable $»^{14}$. L'année suivante, les Goncourt font subir au terme "rococo" une dérivation grammaticale toute personnelle, encore fort révélatrice de l'ironie qui pèse sur l'art du siècle passé : Monselet s'étant amusé, dans un article du

\footnotetext{
${ }^{10}$ Le Cousin Pons (1847), La Comédie humaine, texte établi par M. Bouteron, Paris, Gallimard, « Bibliothèque de la Pléiade », 1951-1959, VI, p. 710.

${ }^{11}$ Celle-ci et celle-là (1833), Les Jeunes France, op. cit., p. 138.

${ }^{12}$ Les Mystères de Paris, Paris, Ed. Libres / Hallier, 1978, t. IV, partie VIII, p. 10. Les Mystères de Paris parut en feuilleton dans Le Journal des Débats de 1842 à 1843.

${ }^{13}$ La Peau de Chagrin (1831), La Comédie humaine, op. cit., t. IX, p. 81.

${ }^{14}$ Lettre à Ernest Feydeau, fin novembre 1857, Correspondance, Ed. Présentée et annotée par J. Bruneau, Paris, Gallimard, «Bibliothèque de la Pléiade», 1973-1997, t. II, p. 782. Flaubert utilise également dans sa Correspondance le terme, peu courant, de «rococoterie»: «Je te défie de me citer une faute échappée, une omission de quelque grand'œuvre, ça se pourrait encore; mais un anachronisme, une rococotterie, une cochonnerie, cela est impossible » (Lettre à Ernest Chevalier, 15 juillet 1839, Correspondance, op. cit., I, p. 46)
} 
Figaro paru le 25 juillet $1858^{15}$, à offrir une petite saynette montrant les deux frères à l'affût d'objets du XVIII ${ }^{\mathrm{e}}$ siècle, les Goncourt notent dans leur journal : «ce matin, Monselet nous fait une blague assez drôle dans le Figaro. Il nous costume et nous charge en rococotiers du XVIII ${ }^{\mathrm{e}}$ siècle, furieux et enragés ${ }^{16}$.

Si le mot devient péjoratif au sens figuré, il n'est pas loin de le rester au sens strictement propre : les écrivains, quel que soit l'attrait que le passé puisse exercer sur eux, se départent rarement d'une certaine ironie - on pourrait parler de condescendance - vis-à-vis de l'esthétique rococo. Dans un des récits fantastiques de Théophile Gautier, Onuphrius, poète romantique venu réciter ses textes à une soirée mondaine, se voit forcé par le diable de débiter des vers vieillots dans le goût de Dorat, de Boufflers, de Bernis et du chevalier de Pezay, poésie que le héros compare à « une substance mousseuse et rosâtre, assez semblable à la crème qui remplit les meringues $»^{17}$, et qu'il qualifie d' «odieuse mixture en friperies mythologiques, et en madrigaux quintessenciés $»^{18}$, tandis que l'auditoire ravi reconnaît «un délicieux pastiche, un admirable pastel, du Watteau tout pur, de la Régence à s'y tromper, des mouches, de la poudre et du fard », enfin un morceau «d'un rococo admirable » ${ }^{19}$. Opposé aux «pensées neuves, [aux] belles rimes d'Onuphrius, diaprées de mille couleurs romantiques $»^{20}$, l'art rococo apparaît dans ce texte comme un art suranné, mièvre, insipide, sans réelle valeur esthétique, goûté par un public large et peu exigeant. C'est souvent ainsi qu'il est considéré dans les milieux littéraires du XIX ${ }^{\mathrm{e}}$ siècle. L'emploi de Pompadour ne fait que confirmer ce dédain : Flaubert se montre plein de mépris envers les artistes qui, à l'image du héros de Gautier en prise avec le diable, renoncent aux beautés d'un art moderne pour redorer les rimes anciennes et le vieux style. Dans une lettre à Louise Colet, l'auteur reproche à Sainte-Beuve, à l'occasion d'une métaphore au cours de laquelle l'histoire de la littérature française est rapprochée de l'évolution des différentes formes de bottes à travers le temps, de revenir aux formes du passé, à un genre «mièvre, léger, contourné. Le talon est si haut que l'aplomb manque $»^{21}$ :

Sainte-Beuve ravaude ces guenilles, dédaigne le connu et, ajoutant du fil et de la colle, continue son petit commerce (renaissance des talons rouges, genre Pompadour et Arsène Houssaye $^{22}$, etc. ). Il faut jeter toutes ces ordures à l'eau, et revenir aux fortes bottes ou aux pieds nus $(\ldots)^{23}$

A son ami Louis Bouilhet, qui vient de voir refuser son drame en vers, Madame de Montarcy, par le comité de lecture du Théâtre Français, l'auteur écrit quelques années plus tard:

Les obstacles que tu rencontres me confirment dans mes idées. Toutes les portes s'ouvriraient, si tu étais un homme médiocre. Au lieu d'un drame en cinq actes, à grands effets de style corsé, présente une petite comédie - Pompadour - agent de change, et tu verras quelles facilités, quels sourires! quelles complaisances pour l'œuvre et pour

\footnotetext{
${ }^{15}$ Le Figaro, jeudi 25 février 1858, $5^{\text {ème }}$ année, n³16, pp. 5-6.

${ }^{16} 24$ février 1858, Journal, Mémoires de la vie littéraire, texte intégral établi et annoté par R. Ricatte, Monaco, Imprimerie nationale de Monaco, 1956, t. II, p. 201.

${ }^{17}$ Onuphrius (1832), Les Jeunes-France, op. cit., p. 63.

${ }^{18}$ Ibid.

${ }^{19}$ Ibid., p. 64 Déjà, dans un court récit fantastique paru en 1831, Gautier affirmait ses distances vis-à-vis de l'esthétique du XVIII ${ }^{\mathrm{e}}$ siècle à l'occasion d'une description d'un intérieur où se trouvaient, disait l'artiste, des «meubles surchargés d'ornements de rocaille du plus mauvais goût» (La Cafetière, L'ouvre fantastique, Nouvelles, Paris, éd. M. Crouzet, Classiques Garnier, 1992, I, p. 12).

${ }^{20}$ Onuphrius, op. cit., p. 84.

${ }^{21}$ A Louise Colet, 26 août 1853, Correspondance, op. cit., II, p. 419

${ }^{22}$ Arsène Houssaye avait fait paraître un nombre important d'écrits (romans, pièces de théâtre, biographies, critiques d'art) sur le XVIII ${ }^{\mathrm{e}}$ siècle, dont il se veut le spécialiste.

${ }^{23}$ A Louise Colet, 26 août 1853, Correspondance, op. cit., II, p. 420.
} 
l'auteur! Ne sais-tu donc pas, que dans ce charmant pays de France, on exècre l'originalité ! ! $^{24}$

Le retour du rococo est ici amplement reconnu, en même temps que fortement critiqué comme une tendance à la facilité, une concession faite à un public médiocre.

Dans le domaine de la critique picturale, l'art rococo, s'il connaît à partir de 1830 un nouveau succès, essentiellement à travers les peintures de Watteau ${ }^{25}$, ne bénéficie pourtant pas d'une image franchement prestigieuse. Malgré les qualités reconnues aux peintres du siècle de la Pompadour, et l'accès de Watteau au statut de représentant d'un temps enchanteur, l'art du XVIII ${ }^{\mathrm{e}}$ siècle est toujours relégué au rang d'art mineur, tenant davantage de la décoration et du divertissement que d'un réel travail artistique. Houssaye ne se lasse pas d'évoquer les maîtres du XVIII ${ }^{\mathrm{e}}$ siècle, auxquels il consacre de nombreux articles sous la monarchie de Juillet, et dont il chante les nombreux talents. Mais la place qu'il leur réserve parmi les peintres français n'est pourtant pas de premier choix :

Dans l'histoire de la peinture en France aux dix-septième et dix-huitième siècle, on voit deux écoles ou plutôt deux familles de peintres se produire presque en même temps et régner tour à tour. L'une, grande et forte, qui puise sa vie dans les saintes inspirations de Dieu et de la nature, qui embellit encore la beauté humaine par le souvenir du ciel et la lumière de l'idéal. L'autre gracieuse et coquette, qui n'attend pas l'inspiration, qui se contente d'être jolie, de sourire, de charmer même aux dépens de la vérité et de la grandeur. Qu'importe si elle n'est pas la beauté pure et naïve où rayonne le divin sentiment; elle ne cherche qu'à séduire. La première famille représente l'art dans toute sa splendeur, la seconde n'est que le mensonge de 1 'art. ${ }^{26}$

Pour représenter la première école, Arsène Houssaye ne voit dans le XVIII ${ }^{\mathrm{e}}$ siècle que le peintre Van Loo, les autres se caractérisant essentiellement par la joliesse de leurs ouvres et le mensonge de leur art. Tout en reconnaissant des qualités particulièrement appréciables aux peintres galants, Houssaye relève sévèrement leurs faiblesses : «Boucher, le dernier mot du dévergondage et de la séduction », « le menteur par excellence » ${ }^{27}$, a ouvert « une école fatale à tout ce qui est noblesse, grandeur et beauté, mais non pas dénuée d'une vraie grâce coquette, d'une vraie magie de couleur, enfin d'un charme inconnu jusque là ${ }^{28}$. Pour ce qui est de Lancret, «avec son esprit et sa patience, [il] n'a été qu'un échec, un rayon dans l'eau, un clair de lune ${ }^{29}$; enfin «Baudouin, né trop faible pour s'élever au-dessus du goût de son temps, se contenta d'être, comme les autres, un mauvais peintre plein de séduction $»^{30}$. L'admiration que l'écrivain voue à Watteau ne va pas non plus sans restrictions : s'il juge que ce dernier ne bénéficie pas de toute la considération que son talent requiert, il ne va pas cependant jusqu'à considérer Watteau comme un artiste sérieux : novateur, enchanteur tant que l'on veut, l'art du peintre galant n'est cependant pas pour lui du grand art, puisqu'il considère que ce dernier

\footnotetext{
${ }^{24}$ A Louis Bouilhet, 30 septembre 1857, Correspondance, op. cit., t. II, p. 597.

${ }^{25}$ Sur la redécouverte de Watteau et des peintres galants au XIX ${ }^{\mathrm{e}}$ siècle, voir H. Adhémar, « Les amateurs de Watteau et le goût pour ses peintures aux XVIII et XIX ${ }^{\mathrm{e}}$ siècles », Watteau, sa vie, son ceuvre, Paris, Ed. Tisné, 1950, pp. 139-160 ; S.O. Simches, Le Romantisme et le goût esthétique du XVIIIe siècle, Paris, P.U.F., 1964, pp. 7-47 ; J.P. Bouillon, «Les Goncourt : apparence et sensibilité », L'Art du XVIIIe siècle et autres textes sur l'art, (1967), Paris, Hermann, 1997, pp. 11-33 ; J.H. Bornecque, « la connaissance et la symbolique de Watteau avant Verlaine », Lumières sur les fêtes galantes de Paul Verlaine, Paris, Nizet, 1969, pp. 20-45 ; D. Posner, «Watteau mélancolique : la formation d'un mythe », Bulletin de la Société de l'Histoire de l'Art Français, 1973, pp. 345361 ; F. Hanskell, op. cit., pp. $103-109$;125-127 ;159-161;176.

26 «Boucher. La Peinture sous Louis XV », La Revue des Deux Mondes, 1843, t. III, p.70.

${ }^{27}$ Ibid., p. 72.

${ }^{28}$ Ibid., p. 71

${ }^{29}$ A. Houssaye, « La Peinture au dix-huitième siècle », L'Artiste, 1844, $4^{\text {ème }}$ série, II, art. cit., p. 134.

${ }^{30}$ Ibid., p. 135.
} 
«n'eut jamais la pensée de renouer la chaîne d'or brisée à la mort de Lesueur, il se contentait d'être gracieux et spirituel $»^{31}$. Ainsi les louanges, globalement très enthousiastes, s'accompagnent toujours de sévères nuances. L'école des Watteau, des Boucher et des Fragonard apparaît comme l'école de la grâce, dont certains écrivains, attirés par le XVIII ${ }^{\mathrm{e}}$ siècle, apprécient le charme, mais qu'ils placent au dessous d'une école parallèle, seule, finalement, même si l'enjeu n'est pas si explicitement présenté, à accéder à l'art véritable ${ }^{32}$. En 1860, Chamfleury parle des œuvres des peintres galants comme d'un « art de troisième ordre qui avait sa raison historique et sociale, mais qu'il ne faut regarder que comme une amusette $»^{33}$. Voilà l'esthétique rococo reléguée bien bas dans l'échelle de l'art, et la pensée d'un bon nombre d'écrivains de l'époque très exactement résumée.

C'est pourtant, paradoxalement, ce statut d'art secondaire - ou tertiaire si l'on en croit Champfleury - qui va faire la force du rococo, en lui permettant de bénéficier finalement d'une image valorisante, sans se départir de ses nuances obsolètes, pour un nombre très significatif d'auteurs sous la monarchie de Juillet. Les changements qui s'opèrent, dans l'évolution du romantisme, dès les années 1830 , se font avant tout contre une forme trop figée et trop imposante de l'art, et en faveur d'une liberté et d'une légèreté plus grandes. Or ce sont précisément ces qualités qui créent, pour de nombreux romantiques, toute la spécificité de l'art du XVIII , ainsi que l'indique parfaitement ce commentaire d'Arsène Houssaye :

Le Beau est absolu, mais il est divers. (...) C'était là l'esprit des sculpteurs et des peintres du XVIII ${ }^{\mathrm{e}}$ siècle. C'est ce qui donne aux œuvres de ce temps trop décrié je ne sais quelle liberté de touche et quelle gaieté de création qui font pardonner les plus beaux barbarismes. Il n'y a pas un pédant dans les ateliers. Si l'on pêche, c'est par l'exemple et le sans-souci des règles. ${ }^{34}$

Cette recherche d'une beauté originale, ainsi que cette gaieté et ce refus des règles, attribuées à l'art rococo, correspondent aux nouvelles orientations de la littérature à l'époque que nous envisageons.

En effet le romantisme adopte, sous la monarchie de Juillet, un nouveau visage, qui ne se montre pas toujours indifférent aux productions artistiques du siècle passé. Nous assistons, à partir des années 1830, et malgré les réticences que nous avons relevées, à une reconsidération de l'art du XVIII ${ }^{\mathrm{e}}$ siècle, et le terme rococo soudain se pare, dans certains textes, de significations positives que ne laissaient pas présager ses tout premiers emplois.

\footnotetext{
${ }^{31}$ Ibid., p. 129.

${ }^{32}$ Cette réaction se retrouve dans les articles de Delécluze, qui en 1852 par exemple, oppose le phénomène de mode en faveur des peintures rococo à l'art noble de Lesueur, Poussin et David : « qu'il y a loin de ces hommes forts et qui ont tiré tout d'eux-mêmes à nos jeunes imitateurs de Watteau et de Boucher, qui, en 1852, abusent d'un talent parfois remarquable pour nous peindre des messieurs en habits couleur gorge de pigeon, et des petites femmes à taille de guêpe et à jupes en paniers, niais et insignifiant réchauffé des vêtements à la mode il y a un siècle, lorsque Louis XV oubliait la duchesse de Mailly pour la marquise de la Tournelle. En bonne conscience, sont-ce de telles mœurs et de si grotesques accoutrements qui doivent devenir le beau idéal des peintres d'un pays tel que la France ? Et ne sera-ce pas justice pure si l'Etat s'abstient d'encourager un genre qui a déjà flétri l'art de la peinture et qui pourrait la perdre ?» (8 juillet 1852, Journal des débats) ; cette mésestime, ainsi que nous l'avons déjà souligné avec l'exemple de Houssaye, est partagée par ceux-là même qui apprécient l'art du passé, et en particulier celui de Watteau : P. Ambly, qui s'intéresse à la critique d'art de Diderot, reconnaît des qualités à la peinture de Greuze et de Chardin, mais se montre plus sévère à l'égard d'un certain nombre d'autres peintres : «Boucher voulait continuer Watteau ; mais de son élégance, il avait fait de la fadeur, et, malgré son faire délicat, savant, séduisant même dans les détails, il est resté le type du mauvais goût. Son gendre Baudouin allait jusqu'à la gravelure, Lancret est plus sage, mais plus lourd et il peint avec moins de fraîcheur » («Diderot et les peintres du XVIII ${ }^{\mathrm{e}}$ siècle », L'Artiste, $1853,5^{\text {ème }}$ série, X, p. 41).

33 « Nouvelles recherches sur la vie et l'œuvre des frères Le Nain », Gazette des Beaux-Arts, 15 décembre 1860.

${ }^{34}$ Houssaye, « La Peinture au dix-huitième siècle », art. cit., p. 136.
} 
1830 marque l'entrée d'un nouveau groupe romantique, «plus jeune et plus agressif que les précédents ${ }^{35}$, sur la scène littéraire française ; à l'ère des Lamartine, Hugo, Vigny, succède une «nouvelle saison du romantisme $»^{36}$, représentée par des artistes nés dans les années 1810, tels que Théophile Gautier, Alfred de Musset ou Gérard de Nerval, qui réorientent les différentes options de la littérature moderne. Dès les premières années de la monarchie de Juillet, les Jeunes France ${ }^{37}$, déçus par l'orientation bourgeoise que prit très vite le nouveau régime, opposent à la médiocrité et à l'utilitarisme ambiants une outrance vestimentaire et une excentricité artistiques destinées à marquer leur différence et à les élever au-dessus d'une réalité prosaïque. Après le petit Cénacle des Jeunes France, qui se désagrège rapidement, la Bohème du Doyenné réunit à nouveau des artistes autour du culte de l'art pour l'art.

Ce romantisme plus jeune se signale principalement par une conception plus ludique et plus fantaisiste de la littérature. Les critiques qui ont décrit le Petit Cénacle ou Le Doyenné évoquent tous les notions de désordre, de vie, d'ironie, de plaisir, éloignées de tout dogme et de toute doctrine. «... La première bohème artiste, écrit Michel Crouzet à propos des Jeunes France, le premier groupement des « marginaux » du beau (...) veulent vivre leur poésie, faire d'eux-mêmes et de leur existence une œuvre d'art, une merveille, imposer partout leur outrance, leur insolence, leur différence ${ }^{38}$; et René Jasisnski, à propos du Doyenné :

(...) Le Doyenné rompait avec une large part du romantisme, celle qu'il appelait « l'école de la pâleur et des crevés ${ }^{39}$. Hors des ténébreux domaines, tandis que s'effaçait le souvenir des barricades, du choléra, et de tous les troubles passés, il ouvrait la littérature à la lumière et à la joie. Malgré les heures d'orage et de deuil il était gai, non plus de ce rire satanique si répandu les années précédentes, mais d'une gaieté franche, tonique, toute de bonne humeur et de jeunesse. Plus de fronts blêmis, de regards noyés, de pâleurs immatérielles : on se donnait aux plaisirs de la chair, on rêvait les contours opulents et les couleurs vermeilles. ${ }^{40}$

L'art, comme les mœurs, réclame plus de liberté et plus de franche gaieté. «le romantisme des "Mages", écrit Pierre Moreau, a opposé de grands rêves à la société de l'époque Louis-Philippe. Contre elle, le romantisme de l'art pour l'art a protesté par la vie, la tenue, le ton. Il a affecté une élégance dédaigneuse, le cynisme, le désordre ${ }^{41}$. Jeunes France et artistes bohèmes, dans les années 1830-1840, valorisent une littérature qui fuit le sérieux et adoptent 《le principe de la dissonance et de la disconvenance ${ }^{42}$. Le caprice de l'auteur est seul garant de l'œuvre, et la fantaisie se fait principe d'écriture : «Moi, je soutiens qu'il faut laisser le champ tout à fait libre à l'auteur, et que la fantaisie doit régner en souveraine ${ }^{43}$, proclame le héros de Mademoiselle de Maupin. La fantaisie, comprise comme synonyme de liberté créatrice, d'écart par rapport aux codes de l'art sérieux, investit ainsi la littérature des

\footnotetext{
${ }^{35}$ P. Bénichou, Le Sacre de l'écrivain, 1750-1830. Essai sur l'avènement d'un pouvoir spirituel laïc en France, Paris, Corti, 1985, p. 427.

${ }^{36}$ Ibid., p. 428.

${ }^{37}$ Sur les Jeunes France et leur place dans le contexte socio-politique de l'époque, on peut voir en particulier la notice de P. Tortonese (T. Gautier, Euvres, Paris, Laffont, 1995, pp. 1545-1548) ou celle de P. Whyte dans l'édition citée (T. Gautier, Romans, contes et nouvelles, op. cit., pp. 1242-1247).

38 M. Crouzet, «Théophile Gautier et le paradoxe du cliché », Présentation, Les Jeunes France, Romans goguenards, Paris, Séguier, 1995, p.11.

${ }^{39}$ L'expression est de Gautier, dont les Goncourt rapportent les propos dans leur Journal (9 avril 1866, op. cit., t. VII, p. 176).

${ }^{40}$ R. Jasinski, Les Années romantiques de Théophile Gautier, Paris, Vuibert, 1929, p. 275.

${ }^{41}$ P. Moreau, Le Romantisme, Histoire littéraire de la France, Paris, del Duca, 1957, p. 282.

${ }^{42}$ M. Crouzet, "Théophile Gautier et le paradoxe du cliché", op. cit., p. 19.

${ }^{43}$ Mademoiselle de Maupin (1835), texte complet avec une introduction et des notes par A. Boschot, Paris, Garnier frères, nouvelle édition, 1955, p. 244.
} 
"cadets du romantisme" dès les années $1830^{44}$. Apparu avec la monarchie de Juillet, à l'heure où le premier romantisme s'essouffle, le mouvement se trouve pleinement installé au cours des années 1850 : dans la préface des Romans et nouvelles (1850) d'Emmanuel de Lerne ${ }^{45}$, Arsène Houssaye affirme :

Il y a aujourd'hui parmi nous une dixième Muse, la Fantaisie, qui règne impérieusement tout enivrée d'aube et de rayons, d'azur et de rosée, de sourires et de larmes, couronnée de pampre vert et de bleu des nues, traînant dans l'herbe en fleurs ses pieds de Diane chasseresse. Elle est née il y a vingt ans sous le souffle des poètes ; Alfred de Musset l'a saluée à son berceau ; Théophile Gautier l'a adorée ; elle s'est promenée dans l'atelier des peintres $(\ldots) .^{46}$

Plus loin, Houssaye nous offre une belle définition de la Fantaisie : elle prend pour lui l'aspect d'une «Muse toujours jeune, folie charmante, reine de l'imprévu, femme et chimère qui a pour patrie l'imagination ${ }^{47}$. Folie, imagination, poésie, raillerie contre le bon sens, telles sont les caractéristiques que prend la Fantaisie dans la littérature du temps, où elle s'incarne dans une écriture capricieuse, sans but, vivante, fuyant les règles et s'épanouissant dans des raffinements de styles.

Fantaisie, excentricité, liberté, ces différentes notions invoquées pour tenter d'appréhender les nouvelles formes du romantisme ne sont pas étrangères, loin s'en faut, à l'esthétique rococo. La nouvelle génération romantique se prononce en faveur de principes esthétiques, avec lesquels l'art maniéré du XVIII ${ }^{\mathrm{e}}$ siècle présente de nombreux points communs. Il ne s'agit pas ici d'opérer une adéquation, qui serait bien abusive, entre l'art rococo et le romantisme "fantaisiste" et "art pour l'art" : ce serait réduire bien arbitrairement la portée de la littérature dans les années 1830-1840, et en nier la profonde originalité. Cependant, un rapprochement peut être établi entre l'attitude littéraire adoptée par les artistes à cette période du $\mathrm{XIX}^{\mathrm{e}}$ siècle, et les principes auxquels répondent les manifestations rococo, permettant de mieux comprendre dans quelles conditions et de quelle façon l'art d'abord si dénigré du XVIII ${ }^{\mathrm{e}}$ siècle a pu connaître, à ce tournant du courant romantique, une nouvelle considération. Le rococo relève d'une esthétique du caprice et de l'irrégularité qui correspond tout à fait aux valeurs recherchées par ceux que l'on a appelé les Petits Romantiques.

On sait que le Doyenné, «Royaume de la fantaisie» pour Houssaye, se tournait volontiers vers le XVIII ${ }^{\mathrm{e}}$ siècle : «(..) A la rue du Doyenné, le moyen âge fut laissé de côté pour le XVIII ${ }^{\mathrm{e}}$ siècle: Théophile Gautier, Gérard de Nerval, Arsène Houssaye, le peintre Camille Rogier, évoquèrent tout un monde galant qu'ils rendaient plus romanesque encore

\footnotetext{
${ }^{44}$ Évoquant la monarchie de Juillet, le chroniqueur Emile Chasles remarque : «la Fantaisie (...) s'empare du pouvoir à cette époque, et si vous voulez recueillir vos souvenirs, vous vous rappellerez quelle influence toute puissante elle exerce alors, non seulement sur les romans et les drames, mais sur la vie et le caractère des écrivains : c'est une épidémie de paradoxes; chacun veut briser sa petite maille du réseau social, sans intention criminelle, sans méchanceté noire, par divertissement et pour marquer son indépendance. S'affranchir de la loi commune, railler le bon sens, abattre un préjugé, étonner surtout, devient un art et une délectation sans égale » («La Fantaisie dans la critique, M. Jules Janin », Revue européenne (1859), t. I, p. 117, cité par J. Landrin, Jules Janin, conteur et romancier, Paris, Les Belles Lettres, 1978, p. 602). Dans La Fantaisie de Victor Hugo, JeanBertrand Barrère met la fantaisie en relation avec la Bohème du Doyenné et les artistes qui composent ce qu'il appelle la «troisième génération romantique »: ceux qu'on appelle encore du nom d'école de l'art pour l'art, n'ont pas cessé la lutte commencée depuis 1832 et accentuée en 1843 contre l'école du bon sens. Occupant la place laissée libre par le silence ou l'apparente abdication du maître, ils accaparent les revues et constituent ce que Sainte-Beuve va appeler un « rameau détaché du romantisme » qui groupera bientôt avec Nerval, Gautier, Banville et Arsène Houssaye autour de la revue L'Artiste, que ce dernier dirige, l'école "fantaisiste" » (J.-B. Barrère, op. cit., p. 390).

${ }^{45}$ Il s'agit du pseudonyme d'Emmanuel Boucher.

${ }^{46}$ A. Houssaye, Préface des Romans et nouvelles par E. de Lerne, Paris, V. Lecou, 1850, p. 6.

${ }^{47}$ Ibid., p. 9.
} 
que ne le comportent Crébillon fils et Boucher ${ }^{48}$, se souvient Champfleury, pour qui les artistes du Doyenné font figure d'《enthousiastes du fard et des mouches » ${ }^{4}$. Le frivole devenant un gage de bon ton, les amours galantes et les fêtes pétillantes d'un siècle futile font inévitablement partie des sujets de prédilection des écrivains ralliés à un romantisme plus léger et plus vigoureux, et l'on voit aisément comment le XVIII ${ }^{\mathrm{e}}$ siècle tel qu'il est perçu au $\mathrm{XIX}^{\mathrm{e}}$, lieu de galanterie, de gaieté et de frivolité, devient un sujet privilégié du mouvement fantaisiste. Mais outre l'intérêt porté à un sujet frivole, deux options majeures du nouveau romantisme favorisent de manière particulièrement efficace la reconnaissance du rococo : le choix de la courbe et du "zigzag" comme forme privilégiée de l'art, et la valorisation de l'art pour l'art, c'est-à-dire, selon la définition de Marcel Voisin, «une libération de l'art à l'encontre de la férule des censeurs (...), des règles d'un classicisme décrépit, de l'emprise d'un moralisme grandissant et de cette curieuse idéologie qui prétend de plus en plus que 1 'artiste a une fonction sociale et politique à jouer ${ }^{50}$.

Les écrivains de 1830 se montrent curieux d'une littérature secondaire, qui se développe à l'écart de la littérature conventionnelle, moins prisée qu'elle sans doute, mais aussi moins rigide et plus originale ; ils s'intéressent alors à toutes les formes marginales d'expression. Ainsi Nerval subit le charme de la poésie des chansons populaires ; mais nous nous intéresserons surtout à Théophile Gautier, dont la préface à Mademoiselle de Maupin constitue une référence essentielle pour le romantisme de 1830, et qui adopte des choix littéraires révélateurs des changements en cours à cette époque. L'écrivain attire notre attention sur les Grotesques, ces artistes méconnus du XVII ${ }^{\mathrm{e}}$ siècle qui accueillaient dans leurs œuvres toutes les nuances de la vie : «beaucoup moins soucieux de pureté classique que les écrivains de premier ordre, [les auteurs de troisième ordre] donnent dans leur composition une bien plus large place à la fantaisie, au caprice régnant, à la mode du jour, au jargon de la semaine $»^{51}$. La variété, l'irrégularité, deviennent principe de beauté. Dans certaines de ses productions, Gautier favorise lui-même l'expression d'une originalité capricieuse, privilégie les parcours déviants, les lignes souples, et adopte le zigzag comme modèle de déploiement, fuyant avant tout :

(...) la ligne droite, celle de toutes les lignes qui déplaît le plus aux gens qui n'ont pas le bonheur d'être mathématiciens ou fabricants de chandelles, et qui ont conservé dans leur âme le sentiment du beau, provenant, comme on sait, de l'emploi des lignes rondes et des zigzags, vérité très connue des enfants qui vont à l'école. ${ }^{52}$

Gérard de Nerval également, dans Le Voyage en Orient, se présente comme «un voyageur qui, trop capricieux pour consentir à suivre la ligne, à peu près droite, des chemins de fer, s'abandonne à toutes les chances des diligences, plus ou moins pleines, qui pourront passer le lendemain! ». La courbe et les libres cheminements du caprice sont considérés par les deux artistes comme les formes privilégiées d'un art qui se veut proche du mouvement de la vie. Ajoutons que Théophile Gautier, lorsqu'il veut définir le genre de beauté mis en œuvre par les Grotesques, a recours à un terme qui renvoie encore à la notion de courbe : l'arabesque, ainsi décrite dans la Préface des Grotesques :

\footnotetext{
${ }^{48}$ Champfleury, Les Vignettes romantiques. Histoire de la littérature et de l'art, 1825-1840, Paris, Dentu, 1883, p. 120.

49 Ibid.

${ }^{50}$ M. Voisin, «Éthique et esthétique de Théophile Gautier : de l'amour de l'art à l'art de vivre », Théophile Gautier, L'Art et l'Artiste, Actes du colloque international de Montpellier, septembre 1982, Montpellier, Presses de l'imprimerie de recherche université Paul Valérie, 1982, t. II, p. 418.

${ }^{51}$ Les Grotesques (1844-1845), Bassac, Plein Chant, 1993, Préface, pp. 9-10.

52 «Un tour en Belgique » (1836), Caprices et zigzags, Paris, Phénix éditions, 1999, p. 60.
} 
En dehors des compositions que l'on peut appeler classiques (...), il existe un genre auquel conviendrait assez le nom d'arabesque, où, sans grand souci de la pureté des lignes, le crayon s'égaye en mille fantaisies baroques. (...) Une guivre griffue, rugueuse, papelonnée d'écailles, avec ses ailes de chauve-souris, sa croupe enroulée et ses pattes aux coudes bizarres, produit un excellent effet dans un fourré de lotus impossible et de plantes extravagantes. Un beau torse de statue grecque vaut mieux sans doute, mais il ne faut pas mépriser la guivre. ${ }^{53}$

On imagine une profusion de formes bizarres, un entrelacs de courbes, des effervescences voluptueuses, qui ne sont pas sans rappeler le rococo, cet art «qui se voue à l'irrégularité et au caprice $»^{54}$, selon les termes de Jean Sgard. Le rapprochement n'a pas échappé à Jean-Claude Brunon, lorsqu'il s'est intéressé a la portée des Grotesques dans l'esthétique de Gautier :

Réhabiliter l'arabesque, c'était (...) au temps de Gautier, renouer avec les fioritures baroques, mais aussi avec le rococo du style Louis XV. C'était certes, ouvrir une voie au Capitaine Fracasse, mais en même temps à Jean et Jeannette, et, plus tard, aux Goncourt. $^{55}$

Le rococo, par la fantaisie de ses inspirations, la surcharge ornementale qui le caractérise, sa prédilection pour la sinuosité des lignes, sa fonction décorative, répond aux attentes d'artistes épris d'une beauté irrégulière, qui sait manifester la vie en son efflorescence heureuse, et qui s'oppose à une beauté froide et conventionnelle. Le terme de baroque, employé par Gautier à propos de l'arabesque, et fréquemment utilisé par les critiques pour mieux définir le style de productions fantaisistes et d'apparence ludiques de la dernière génération romantique ${ }^{56}$, indique assez la relation existant entre l'art rococo et le nouveau romantisme : rococo et baroque sont en effet deux notions extrêmement proches ${ }^{57}$, souvent associées par la critique - Béatrice Didier parle du rococo comme d'une " esthétique baroque exacerbée $»^{58}$-, toutes deux éprises d'originalité, de fantaisie, de liberté, de surcharge ornementale, et de sinuosité dans les lignes. Pour Jean Starobinski également, l'art mignard du XVIII ${ }^{\mathrm{e}}$ siècle s'inscrit dans la droite lignée du baroque :

(...) le style rococo (terme générique où il faut inclure le style rocaille et le style Louis XV) pourrait être défini comme un baroque flamboyant et miniaturisé : il flamboie décorativement à petit feu, il pétille, il puérilise et féminise les images mythologiques de l'autorité. Il est l'exemple même d'un art où l'allègement sémantique, la raréfaction des valeurs signifiées se combinent avec le foisonnement élégant, ingénieux, facile et souriant des formes où le haut baroque du XVII ${ }^{\mathrm{e}}$ siècle avait théâtralement voulu inscrire la souveraineté. ${ }^{59}$

\footnotetext{
${ }^{53}$ Les Grotesques, op. cit., Préface, p. 11.

${ }^{54}$ J. Sgard, art. cit., p. 18 ; «la sinuosité (...) est l'un des éléments constitutifs du rococo », écrit encore J. Starobinski (op. cit., p. 23)

${ }^{55}$ J.C. Brunon, « Arabesque, baroque, caprice. Essai sur la portée des Grotesques dans l'esthétique de Gautier », L'Art et l'artiste, Acte du colloque international de Montpellier, op. cit., II, p. 372.

56 J. Rousset, après avoir opposé le «romantisme intérieur» et le baroque, évoque un romantisme plus «périphérique », qui «porte certains caractères extérieurs au baroque » (La littérature de l'âge baroque en France, op. cit., conclusions, p. 251) ; D. Sangsue reprend cette idée et la développe dans Le Récit excentrique. Gautier, De Maistre, Nerval, Nodier, Paris, José Corti, 1987, p 415).

57 Tout en reconnaissant que « le rococo fut ordinairement interprété comme la dernière, l'extrême phase du baroque », F. Kimball s'inscrit pourtant en faux contre ce lieu commun (voir F. Kimball, op. cit., p. 40). Étudiant la genèse du style, il reconnaît cependant que beaucoup de motifs rococo furent d'origine baroque, mais précise que ceux-ci ont subi des transformations significatives. Dans son article sur les « style rococo et style régence », J. Sgard différencie également les deux notions, qu'il estime « opposé[es] par l'esprit » (J. Sgard, art. cit., p. 18).

${ }^{58}$ Histoire de la littérature française du XVIII ${ }^{e}$ siècle, Paris, Nathan, 1992, p. 68.

${ }^{59}$ J. Starobinski, L'Invention de la liberté (1964), Genève, Skira, 1994, p. 22.
} 
Le rococo se distingue donc en grande partie du baroque par la quasi absence de signification dans le déploiement de ses formes ${ }^{60}$. J. Starobinski oppose le faste du XVII ${ }^{\mathrm{e}}$ siècle, représentatif d'une autorité, aux formes luxueuses du XVIII ${ }^{\mathrm{e}}$ qui ne renvoient à aucun antécédent spirituel $^{61}$. Dans l'art rococo, les formes ne désignent qu'elles-mêmes, et l'artiste peut en jouer à son gré, indépendamment de toute considération pratique, ou transcendantale : nul ordre supérieur n'est suggéré, le plaisir est la seule valeur recherchée. L'art n'est plus qu'agrément de décor, et il s'en trouve moins solennel, plus libre et plus vivant. Moins sérieux, aussi, puisqu'il se concrétise dans des grâces maniérées et d'une profusion souriante. En ce sens, c'est à l'esthétique rococo, nous semble-t-il, plus encore qu'au baroque, que font songer les déclarations et les productions des artistes dans les années 1830-1860; cet art indifférent aux valeurs de confort et d'utilité ne peut que plaire à ceux qui, comme les artistes du Doyenné, ont fait de la préface de Mademoiselle de Maupin, violent réquisitoire contre «Messieurs les utilitaires » ${ }^{62}$, leur manifeste, et Michel Crouzet n'a pas manqué de souligner les rapports qu'entretient cette esthétique du caprice avec l'art pour l'art: «le nouveau romantisme du Doyenné, fantaisiste, plastique, art pour l'art, se met dans la filiation rococo, le $\mathrm{XVIII}^{\mathrm{e}}$ siècle lui semble avoir connu le vrai beau, non utilitaire, aristocratique, pas prêcheur social ou moral, mais élégant, voluptueux, maniéré ${ }^{63}$, remarque-t-il dans sa Notice sur Omphale. Si l'on peut incontestablement parler de «filiation», il faut cependant se garder d'opérer une trop grande équivalence entre le rococo et l'art pour l'art : outre les nuances fort sensibles dans les productions issues de ces deux esthétiques, la place que celles-ci accordent à la beauté est loin d'être la même. L'art, selon les petits romantiques, doit être libre, fantaisiste et autonome; il n'en met pas moins l'artiste en contact avec une beauté supérieure à la simple joliesse pompadour : "ce qui est certain, écrit Albert Cassagne, c'est que la beauté, quelle que soit sa nature et sa provenance, est une porte ouverte sur l'idéal, c'est-àdire un infini d'émotions et de jouissances dont la richesse contraste heureusement avec la réalité triste, monotone et bornée ${ }^{64}$. Autant que par leur goût pour les formes inutiles et irrégulières, les écrivains adeptes de l'art pour l'art se signalent par le culte qu'ils vouent à la beauté, transcendante et éternelle, qu'ils placent au cœur de toute recherche artistique. Cette beauté n'est cependant ni abstraite, ni conventionnelle, et peut s'épanouir dans les formes les plus variées : «nous n'avons pas affaire à des esthéticiens, mais à des hommes d'impression, à des esprits intuitifs pour qui l'essence et la nature du beau importe peu ${ }^{65}$, précise encore A. Cassagne. Il reste que bien souvent les artistes, à côté de productions fantaisistes dans lesquelles s'affirme leur goût pour une littérature mineure et excentrique, se consacrent à la réalisation d'œuvres extrêmement travaillées. Ainsi le romantisme "fantaisiste" se propose-t-il malgré tout des ambitions autres que l'art rococo; mais il trouve, dans les principes esthétiques du passé, l'expression de certaines valeurs qu'il défend ardemment et par lesquelles il se distingue de ses prédécesseurs immédiats.

\footnotetext{
${ }^{60} \mathrm{~J}$. Sgard fait également remarquer que, si l'art louis-quatorzien comme l'art rococo était un art du décor, au $\mathrm{XVIII}^{\mathrm{e}}$ siècle, «ce n'est plus un décor de "montre", mais un décor sensible et suggestif, propre à créer cette impression de charme, de grâce, de léger vertige qui reste lié au style Régence. Dans tous les arts, le décor est aimé pour lui-même » (J. Sgard, art. cit., p. 13).

${ }^{61}$ «Cet allégement du contenu laisse le spectateur en présence d'un superflu décoratif, qui charme ou qui scandalise par sa gratuité. La forme ne communique pas de message, elle se manifeste comme pure dépense ; on y trouve à la fois une faiblesse et un excès : le sens est dissipé, ou il n'en reste qu'un impalpable résidu, et toutes les floraisons sensuelles sont d'une exubérance outrée, au gré d'une raison attentive aux seules valeurs de confort et d'utilité. » (J. Starobinski, op. cit., p. 22).

${ }^{62}$ Préface de Mademoiselle de Maupin, op. cit., p. 22.

${ }^{63}$ M. Crouzet, Notice d'Omphale, L'Euvre fantastique, op. cit., I, pp. 56-57

${ }^{64}$ A. Cassagne, La Théorie de l'art pour l'art en France chez les derniers romantiques et les premiers réalistes (1906), Paris, Chmap Vallon, 1997, p. 201.

${ }^{65}$ Ibid., p. 200-201.
} 
Gautier, en particulier, s'est plus d'une fois prononcé en faveur d'un art purement ornemental, dont il rédige un éloge enthousiaste à l'occasion du compte rendu de l'édition de L'Imitation de Jésus Christ par Curmer :

En feuilletant ce magnifique volume, nous avons fait quelques réflexions sur cet art particulier, qu'on nomme l'ornement, et auquel on n'attache pas communément une importance philosophique assez grande. De tous les arts, c'est celui qui contient le plus de création. Il n'a pas comme le statuaire, comme la peinture, son point de départ dans la réalité ; il n'est pas nécessaire comme l'architecture, c'est-à-dire résultant de certains besoins de l'homme et de certaines lois de statique ; (...) il existe à part, en dehors de tout, avec des formes variables à l'infini, et dont le modèle précis ne se rencontre nulle part. Rien n'est plus chimérique que le monde de l'ornement, monde complet, qui a sa flore et sa faune, son herbier et son bestiaire, son émaillerie et sa joaillerie, et qui n'emprunte à la nature que des thèmes lointains, modifiés et variés de mille manières. (...) ce qu'il y a de plus difficile au monde, c'est d'imaginer quelque chose en dehors de ce qui existe. L'ornement essaye de résoudre ce problème et invente une création à côté de la création. ${ }^{66}$

L'art décoratif satisfait le rejet que l'auteur éprouve pour l'utilitarisme, et répond à son goût pour la fantaisie créatrice ; lui-même revendique le caractère gratuit de certaines de ses œuvres en $\operatorname{prose}^{67}$; le fait même de qualifier deux de ses récits d' « histoire rococo » (c'est avec ce sous-titre que parut pour la première fois Jean et Jeannette, et c'est également ainsi qu'est qualifié Omphale à partir de 1839, date de sa seconde édition) révèle alors bien plus qu'un simple goût pour une période donnée : l'expression traduit l'estime que Gautier porte à une littérature dite "mineure", qui ne cherche qu'à plaire. En employant cet adjectif, qui, on l'a $\mathrm{vu}$, est toujours empreint à cette époque d'une certaine charge négative, l'auteur annonce que son récit va se dérouler au XVIII ${ }^{\mathrm{e}}$ siècle ; mais il avertit aussi son lecteur qu'il s'essaie à un genre passé de mode, un peu ridicule dans son maniérisme excessif, et que ces histoires ne prétendent pas davantage qu'à retrouver les grâces un peu mièvres et le charme désuet d'un style pittoresque. L'auteur montre ainsi qu'il sait s'amuser par le biais de l'écriture, et qu'il ne répugne pas à s'investir dans des œuvres qui ne valent que pour elles-mêmes et pour les grâces stylistiques qu'elles déploient. Jean et Jeannette et Le Petit chien de la marquise s'affichent comme simples divertissements littéraires, œuvres essentiellement ludiques. Les écrivains ralliés au romantisme fantaisiste valorisent ainsi une littérature qui ne se prend pas au sérieux et qui, plutôt que de se proposer de nobles buts, vise à distraire et à charmer le lecteur. Le plaisir devient le critère exhibé, avec une forfanterie plus ou moins provocatrice, au nez des lecteurs trop sérieux ${ }^{68}$.

\footnotetext{
${ }^{66}$ L'Artiste, 28 février 1858, cité par M. Voisin, Le Soleil et la nuit. L'imaginaire dans l'œuvre de Théophile Gautier, Bruxelles, Ed. de l'université de Bruxelles, 1981, p. 324.

67 Ainsi, dans la préface de Fortunio, écrit-il avec une ironie provocante: «Assurément bien des esprits chagrins, embusqués au tournant de quelque feuilleton, demandent quel est le sens et le but de ce livre. - Il ne manque pas, en ce siècle de chiffres, de mathématiciens qui diraient, après avoir entendu Athalie : "qu'est-ce que cela prouve ?" - Question beaucoup plus légitime après la lecture de Fortunio.

Hélas ! Fortunio ne prouve rien, - si ce n'est qu'il vaut mieux être riche que pauvre, quoi qu'en puissent dire Monsieur Casimir Bonjour et tous les poètes qui font des antithèses sur les charmes de la médiocrité » (Fortunio et autres nouvelles, Introduction et notes d'A. Bouchard, Lausanne, L'Âge d'homme, 1977, Préface, p. 23).

${ }^{68}$ C'est également le statut que Jules Janin revendique pour ses romans qui se déroulent au XVIII ${ }^{\mathrm{e}}$ siècle : Les Gaîtés champêtres, en particulier, se présentent comme l'« œuvre légère » d'un écrivain « qui ne songe qu'à plaire un instant » (Les Gaîtés champêtres, Paris, Lévy, 1961, I, Préface, p. 30), et qui s'estime heureux « d'être placé au premier rang des écrivains de second ordre » (Ibid., p. 35). Nerval présente également certaines de ses compositions comme des œuvres n'ayant d'autre but que celui de distraire le lecteur : ainsi en est-il du Voyage en Orient, où l'auteur évoque le modèle d'écrivains du XVIII ${ }^{\mathrm{e}}$ siècle pour donner une idée plus précise du genre auquel il prétend se rallier: «Tu m'as fait promettre de t'envoyer de temps en temps les impressions sentimentales de mon voyage, qui t'intéressent plus, m'as-tu dit, qu'aucune description pittoresque. Je vais commencer. Sterne et Casanova me soient en aide pour te distraire. J'ai envie simplement de te conseiller de les
} 
Il y a, certainement, une part d'affectation dans ces déclarations ; mais elles sont révélatrices de véritables options littéraires: partisans d'une dimension ludique de la littérature, décidés à rompre avec l'image stéréotypée et austère de l'artiste investi d'une mission, les jeunes écrivains adoptent sous la monarchie de Juillet une attitude résolument désinvolte, qui relève certainement de l'esthétique du dandysme, mais aussi de l'esthétique rococo, si l'on suit la définition qu'en propose Roger Laufer :

Ce style, qui porta l'esprit français à travers l'Europe, une manière de vivre et de penser entre l'indifférence et l'indignation, l'acceptation et le refus, ce style du sourire et de la désinvolture (c'est-à-dire du désengagement), ou plus précisément de la distanciation ironique, je propose de l'appeler le style rococo. ${ }^{69}$

Ainsi, «le rococo est devenu progressivement un élément du romantisme, auquel il s'opposait d'abord, grâce à une partielle intégration ${ }^{70}$. Libre et capricieux, il s'inscrit parfaitement dans le credo d'un Gautier qui déclare: «l'art c'est la liberté, le luxe, l'efflorescence, c'est l'épanouissement de l'âme et de l'oisiveté " ${ }^{71}$. Dans le même mouvement qui les entraîne vers les excentricités du XVII ${ }^{\mathrm{e}}$ siècle, les artistes avouent parfois leur émotion devant les ondoiements et la grâce de l'esthétique rococo. En 1832, un personnage d'une nouvelle de Jules Janin, tout en attribuant au style rococo des qualificatifs péjoratifs, reconnaît son goût, apparemment immotivé, pour les formes contournées de cet art : «le XVIII ${ }^{\mathrm{e}}$ siècle est un siècle bizarre, remarque le personnage; il affecte les petites moulures, les petites facettes, les contorsions de toutes sortes ; il procède par zigzags, il est doré, il est faux, il est mesquin, il est riche et rococo. C'est joli, bête et lascif. (...) Le Jeune homme trouvait tout cela charmant ${ }^{72}$. La réaction suscitée par cette esthétique se caractérise par un mélange de mépris et d'invincible attirance. Petrus Borel, dans un de ses contes immoraux, se livre, dès 1833 , à un éloge moins nuancé et plus enthousiaste de cet art, qu'il oppose à « l'architecture d'Athènes, glacée, nue, constante, rabâcheuse » :

[1'architecture rococo] avait son aspect à elle, sa coquetterie à elle; expression exacte de son époque, elle lui convenait en tout point; et sa physionomie est tellement unique, qu'après la plus longue série de siècles, on reconnaîtra de prime abord ce Roccoco [sic] Louis XIV et Louis XV ; avantage que n'auront pas les funestes et ignorantes copies de l'antique de nos faiseurs contemporains, qui n'impriment aucun cachet à leur époque et n'en reçoivent aucun, si bien que les temps à venir prendront leurs œuvres pour de mauvais antiques dépaysés. ${ }^{73}$

Si Petrus Borel est le premier, parmi les écrivains de son temps, à afficher aussi franchement son attirance pour cette esthétique généralement estimée de mauvais goût, il n'est cependant pas le seul, et nous rencontrons dans la littérature d'autres témoignages enthousiastes: quelques années plus tard, dans un ouvrage paru en 1857 les Goncourt, à l'instar de Pétrus Borel, nomment l'un de leurs chapitres « rococo», et se lancent dans la

relire, en t'avouant que ton ami n'a point le style de l'un ni les nombreux mérites de l'autre, et qu'à les parodier il compromettrait gravement l'estime que tu fais de lui. » (Nerval, Voyage en Orient (1851), Euvres, texte établi et annoté par A. Béguin et J. Richer, Paris, Gallimard, «Bibliothèque de la Pléiade », 1970-1971, II, p. 35. Partie publiée en 1841 dans la Revue de Paris).

${ }^{69}$ R. Laufer, Style rococo, style des Lumières, Paris, Corti, 1963, p. 21.

${ }^{70}$ A. Montandon, «Gautier et Watteau », Antoine Watteau (1684-1721), le peintre, son temps et sa légende, Paris, Genève, Champion Slatkine, 1987, p. 302.

${ }^{71}$ T. Gautier, Préface d'Albertus ou l'âme et le péché, Poésies complètes, publiées par R. Jasinski, Nouvelle édition revue et corrigée, Paris, Nizet, 1970, I, p. 82.

${ }^{72}$ Honestus (paru dans la Revue des Deux Mondes en mai 1832), Contes fantastiques et contes littéraires, ParisGenève, Slatkine Reprints, 1979, p. 49.

${ }^{73}$ P. Borel, Monsieur de l'Argentière, Champavert, Contes immoraux, auvres complètes, Genève, Slatkine Reprints, 1967, III, pp. 42-43. 
description abondante et sinueuse du salon en style hautement Louis XV de Mademoiselle de Riedmassen $^{74}$.

Ces marques d'intérêt ne se limitent pas aux œuvres de fiction. J.-B. Barrère a montré comment le voyage en Belgique provoqua chez Victor Hugo une révélation : «la fantaisie peut habiter la pierre ${ }^{75}$, et l'admiration éprouvée pour les productions rococo joue un rôle fondamental dans cette découverte. En 1837, devant la chaire de Henry Verbruggen, dans l'église Sainte-Gudule à Bruxelles, le poète, qui s'était dans un premier temps déclaré hostile à ce qu'il assimilait au " goût de la Renaissance faisandé ${ }^{76}$, se voit forcé d'admettre :

L'ensemble est prodigieusement rococo et prodigieusement beau. Que les fanatiques du sévère arrangent cela comme ils voudront, cela est. Cette chaire est dans l'art un de ces rares points d'intersection où le beau et le rococo se rencontrent. Watteau et Coypel ont trouvé aussi quelquefois de ces points-là. ${ }^{77}$

La Belgique est également déterminante dans la vision que Gautier se fait de l'esthétique du XVIII ${ }^{\mathrm{e}}$ siècle : touché, un an avant V. Hugo, par l'architecture de certaines maisons Bruxelloises, « où toutes les nuances du rococo espagnol, italien et français » sont représentées, il précise : «je me sers ici du mot rococo faute d'autre, sans y attacher aucun sens mauvais, pour désigner une période d'art qui n'est ni l'antiquité, ni la renaissance et qui, dans son genre, est tout aussi original et tout aussi admirable ${ }^{78}$. L'on tente d'épurer le terme, peu à peu, de ses nuances péjoratives. Ainsi, après 1830 n'est-il plus juste d'évoquer, comme le fait Fiske Kimball dans son ouvrage sur Le Style Louis XV, «le mépris et l'insulte du XIX à l'égard du rococo ${ }^{79}$. Certes, l'art du XVIII ${ }^{\mathrm{e}}$ siècle ne sera jamais considéré comme du grand art; mais on refuse dorénavant de ne considérer que les œuvres classiques et académiques, car «à force de bon goût, on arrive à se priver d'une multitude de sujets, de détails, d'images et d'expressions qui ont la saveur de la vie ${ }^{80}$. Le rococo force l'admiration par l'exubérance des ses formes, et définit un style parallèle de beauté, en marge du Beau absolu : «l'art sous Louis XV, à force de violence, de profusion et d'emportement, finit quelquefois par nous faire dire : c'est laid, mais c'est beau » ${ }^{81}$, reconnaît Victor Hugo, qui en 1839 développe sa pensée :

L'architecture du XVIII ${ }^{\mathrm{e}}$ siècle, quand elle est riche, finit par racheter son mauvais goût. Sa fantaisie végète et s'épanouit au sommet des édifices en buissons de fleurs si extravagantes et touffues, que toute colère s'en va et qu'on s'y acoquine. Dans les climats chauds, à Lisbonne, par exemple, qui est aussi une ville rococo, il semble que le soleil ait

\footnotetext{
${ }^{74}$ «Sur les consoles s'étagent des écuelles de Sèvres aux initiales de Madame de Pompadour, des bols de Chine, coquille d'œuf clissée de filaments de bambou, des filigranes d'argent qui semblent filés par des araignées, des verres de Venise semés d'or, aux procédés de fabrication perdus, des bonbonnières aux émaux de Parpette (...). Sur des jardinières de bambou s'ouvrait un double éventail de camélias blancs. Jamais le roseau n'avait connu plus aérienne barrière ; (...) De luxuriants buissons de roses mousseuses s'étouffaient au col serré de deux vases longs et fluets comme ceux que découpe un pan de ciel bleu sur la tête des canéphores antiques, - deux magnifiques biscuits de Sèvres, pâte tendre. (...) Une bibliothèque d'ébène miniature, de la première manière de Boulle, d'un goût d'incrustation qu'on ne trouve plus, lorsque dans l'ébène l'artiste sertit l'étain et l'écaille, trahissait par la vitrine du vantail supérieur tous les enfants perdus de l'humour sous des maroquins de Bauzonnet. » (Goncourt, En 18..., Euvres complètes, Genève-Paris, Slatkine Reprints, XII-XIV, pp. 120-121).

${ }^{75}$ J.B. Barrère, La Fantaisie de Victor Hugo, Paris, Corti, 1960, p. 286. V. Hugo se montre, nous dit le critique, «saisi de voir que l'art sévère, comme il l'appelle, n'a pas le privilège du beau et de constater que ce fouillis d'ornements, cette exubérance flamande, où il surprend son reflet, cette folle dépense d'imagination a aussi sa beauté » (Ibid., p. 287).

${ }^{76}$ Littérature et philosophie mêlées, Reliquat, cité par J.-B. Barrère, op. cit., p. 287, n 4.

${ }^{77}$ V. Hugo, « France et Belgique », 17 août 1837, Voyages, Euvres complètes, Paris, Laffont, 1987, p. 606.

78 «Un tour en Belgique », Caprices et zigzags (1852), Paris, Phénix éditions, 1999, p. 50.

${ }^{79}$ F. Kimball, op. cit., p. 15.

${ }^{80}$ T. Gautier, Les Grotesques, op. cit., p. 325.

${ }^{81}$ Littérature et philosophie mêlées, Reliquat, cité par J.B. Barrère, op. cit., p. 287, n. 3.
} 
agi sur cette végétation de pierre comme sur l'autre végétation. On dirait qu'une sève a circulé dans le granit; elle s'y est gonflée, s'y est fait jour et jette de toutes parts de prodigieuses branches d'arabesques qui se dressent vers le ciel. ${ }^{82}$

Le goût pour le rococo, fait d'un mélange d'invincible attirance et de persistantes réticences, se révèle également dans le domaine littéraire. De même que les poètes oubliés du $\mathrm{XVII}^{\mathrm{e}}$ siècle sont remis au goût du jour, on réhabilite les auteurs secondaires du XVIII ${ }^{\mathrm{e}}$ siècle: dans les années 1830, «il s'agissait d'inventorier [la] littérature jusque dans les moindres recoins pour en tirer toutes les richesses ${ }^{83}$. Arsène Houssaye contribue amplement, par sa galerie de portraits, à mettre le public en contact avec les auteurs du XVIII ${ }^{\mathrm{e}}$ siècle, dont il offre, au fil des rééditions de son ouvrage, des biographies - souvent fantaisistes - et des commentaires enthousiastes d'ouvrages souvent peu connus. En 1857, Charles Monselet consacre aux écrivains méconnus du siècle passé un ouvrage qu'il intitule : Les Originaux $d u$ siècle dernier. Les oubliés et les dédaignés, destiné à faire revivre "certaines intelligences effacées, égarées ou isolées ${ }^{84}$. Sa préface témoigne de la préexistence d'un important courant en faveur des artistes mineurs du siècle de Louis $\mathrm{XV}$, courant qu'il inscrit dans la redécouverte générale de l'art rococo :

Il nous a semblé $[\ldots]$ que le mouvement d'attention que nous voulions essayer de diriger sur ces écrivains, tombés en disgrâce, avait son équivalent dans le mouvement de vogue qui s'est déterminé, depuis huit ou dix ans, en faveur d'un assez grand nombre d'artistes français du XVIII ${ }^{\mathrm{e}}$ siècle, longtemps négligés, tels que Jeaurat, Chardin, Lépicié, Moreau le Jeune, Debucourt. ${ }^{85}$

La réhabilitation des auteurs secondaires se fait au nom d'une valeur essentielle aux yeux d'écrivains lassés d'un art solennel : la vie ${ }^{86}$. C'est elle qu'ils mettent en avant lorsqu'ils cèdent au charme des productions capricieuses du passé. Ainsi, dans un article de 1850, Sainte-Beuve oppose l'atmosphère démoralisante de René à la lecture vivifiante du roman de Le Sage :

Quand on vient de lire René pour la première fois, on est saisi d'une impression profonde et sombre. On croit se reconnaître dans cette nature d'élite et d'exception, si élevée, mais si isolée, et que rien ne rapproche du commun des hommes. (...) Il n'y a rien de plus opposé à René que Gil Blas : c'est un livre à la fois railleur et consolateur, un livre qui nous fait entrer en plein dans le courant de la vie et dans la foule dans nos semblables. ${ }^{87}$

Les petits auteurs du XVIII ${ }^{\mathrm{e}}$ siècle sont fréquemment cités comme modèles littéraires par certains écrivains désireux d'échapper aux codes traditionnels de l'époque, et adeptes d'une écriture vigoureuse, qui s'émancipe des voies habituelles de l'art pour s'épanouir dans des formes gratuites et irrégulières. Gautier, considérant qu' « il est temps d'en finir avec les maladies littéraires [et que] le règne des phtisiques est passé ${ }^{88}$, se place ostensiblement sous l'influence des romans libertins lorsqu'il écrit Le Petit chien de la marquise, mais aussi en

\footnotetext{
${ }^{82}$ Le Rhin, lettre $29^{\text {ème }}$, fin août 1839, Voyages, Euvres complètes, Paris, Laffont, 1985, p. 313.

${ }^{83}$ R. Jasinski, Les Années romantiques de Théophile Gautier, op. cit., p. 218.

${ }^{84}$ Les Originaux du siècle dernier. Les oubliés et les dédaignés (1857), Paris, Lévy frères, 1864, Préface, p. 1.

${ }^{85}$ Ibid.

${ }^{86}$ Les écrivains réhabilités par C. Monselet «ont cette qualité énorme, la vie, qui fait parfois défaut aux grands maîtres » (Les Originaux du siècle dernier, op. cit., préface, p. 3).

${ }^{87}$ « Gil Blas, par Le Sage », (5 août 1850), Causeries du lundi, Paris, Garnier frères, 1927, t. II, p. 353. Cet autre passage insiste encore sur la vivacité de l'écriture : «l'auteur, dans ce récit étendu, développé et facile, a voulu représenter la vie humaine telle qu'elle est, avec ses diversités et ses aventures, avec les bizarreries qui proviennent des jeux du sort et de la fortune, et surtout avec celles qu'y introduit la variété de nos humeurs, de nos goûts et de nos défauts » (Ibid., p. 360).

${ }^{88}$ Fortunio, op. cit., Préface, p. 24.
} 
prenant pour épigraphe des Jeunes France une citation d'Angola, roman libertin ; de façon plus prononcée que Gautier, et avant lui, Jules Janin se réclame de Crébillon dans la Préface de La Confession, roman d'un jeune homme de 1830 :

C'est à l'exemple de cet écrivain qui n'en est pas un que j'ai imaginé de faire un livre çà et là, marchant au hasard, sans passions, sans événements, sans intrigues. (...) j'ai donc pour premier mérite de n'avoir rien inventé, d'avoir écrit sans plan et au hasard. Ce sera peut-être le seul, mais enfin ce sera toujours un mérite qui ne sera pas perdu pour vous qui en avez su si bon gré à Crébillon. ${ }^{89}$

En 1833, Janin fait paraître dans les Contes nouveaux une étude sur Crébillon, au cours de la quelle il se défend de vouloir restaurer la réputation d'un tel auteur, mais qui traduit pourtant sans ambiguïté le goût qu'il éprouve pour ses petits romans et la liberté de son style. L'écriture décousue de l'auteur, libre et fantasque, fascine Jules Janin, tout comme le pittoresque du personnel romanesque :

je me suis épris de ces romans en deux petits volumes, écrits en grosses lettres et sans permission du censeur. Il n'y a pas de comédie de la Foire, malgré son gros sel, qui vaille ce jargon, ce musc, cet ambre, ce fard, ce vice nu à la peau blanche, ces marquis aux épées de soie, ces vicomtes qui font de la broderie et puis cet ameublement or et perles avec des fleurs qui serpentent; des petits chiens sur de moelleux coussins ; des portraits de famille, et, dans le lointain, la maison du faubourg et les orgies nocturnes. ${ }^{90}$

Marivaux suscite également l'attention d'un certain nombre d'écrivains : il est alors reconnu digne de provoquer l'intérêt du public et d'artistes épris d'originalité littéraire. Ses pièces de théâtre, surtout, connaissent un important succès ${ }^{91}$. Jules Janin ne perd jamais l'occasion de saluer son talent de dramaturge lors des représentations de ses œuvres, mais apprécie aussi ses romans, et goûte parfaitement un esprit pourtant si souvent décrié en son temps ${ }^{92}$. Théophile Gautier se montre également favorable au style particulier de Marivaux, et, comme Janin, réhabilite dans ses feuilletons dramatiques un auteur en butte à d'anciennes et lourdes critiques. Ainsi, à propos des Fausses confidences mises en scène en juin 1848 :

Les gens superficiels se hâtent de dire : «c'est du marivaudage ! » et ce mot, qui fut une injure autrefois, est devenu un éloge aujourd'hui qu'on apprécie plus justement Marivaux. (...) Marivaux est le Watteau du théâtre, et n'est pas Watteau qui veut. ${ }^{93}$

D'autres se font moins unanimes, mais reconnaissent toutefois que le nom de Marivaux mérite de ne pas tomber dans l'oubli, comme Arsène Houssaye par exemple ${ }^{94}$, qui

\footnotetext{
${ }^{89}$ J. Janin, La Confession (1830), Paris, Lévy, 1861, p. 18.

${ }^{90}$ Ibid., p. 2.

${ }^{91}$ F. Deloffre, retraçant l'évolution du mot "marivaudage" au cours du XVIII ${ }^{\mathrm{e}}$ siècle, a souligné cet intérêt chez certains écrivains au cours des années qui nous intéressent et dans les années qui suivent : «en 1877 même, Daudet ne voit encore dans le marivaudage que "l'étiquette d'un genre contourné et moribond". Ce sens dépréciatif n'a pourtant pas subsisté le premier, semble-t-il. Jules Janin, initié par Duviquet, donne du marivaudage une définition flatteuse. Il y voit "un style à lui [Marivaux], vif, ingénieurs, subtil, un langage qui n'était imité de personne". A son tour Gautier en parle en des termes favorables, si bien que pour les contemporains de Verlaine ou des Goncourt le mot de marivaudage résume ce que le XVIII ${ }^{\mathrm{e}}$ siècle a produit de meilleur en fait d'esprit" » (Une préciosité nouvelle, Marivaux et le marivaudage, Paris, Armand Colin, 1967, p. $7)$.

${ }^{92}$ Voir Histoire de la littérature dramatique, Ed. de Paris, 1853-1858, t. II, chapitre 1, « l'esprit de Marivaux », et chapitre 6, « Adieux à Marivaux ».

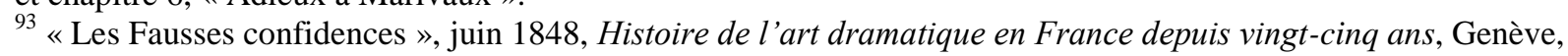
Slatkine Reprints, 1968, V, p. 289.

94 « [Marivaux] peut toujours défier l'oubli : d'abord par son esprit, ensuite par son style, ou plutôt par sa manière d'écrire » (Les hommes d'esprit, Galerie de portraits du XVIII siècle, $6{ }^{\text {ème }}$ édition, revue et corrigée, Paris, Hachette, 1858, p. 88. L'article sur Crébillon parut dans L'Artiste en 1853).
} 
offre dans sa galerie un long portrait de l'écrivain, ou Sainte-Beuve, qui en 1854 lui consacre deux articles. Ces derniers ne sont pas dénués d'ambiguïté bn: tout talentueux qu'il soit, Marivaux est dépourvu, selon Sainte-Beuve, de génie véritable. Le critique perçoit dans le style et dans la pensée de l'auteur des défauts impitoyablement dénoncés ${ }^{95}$. Aussi, que l'on ne s'y trompe pas : «il y a lieu de le relire, de lui rendre justice sur plus d'un détail, de sourire à ses finesses exquises et à ses grâces pleines de concert et de mignardise, mais non point de l'aller réhabiliter ${ }^{96}$. Les éloges, dans le texte de Sainte-Beuve, doivent donc être pris pour ce qu'ils sont : des concessions faites à un écrivain secondaire mais agréable à feuilleter. Ils sont néanmoins solidement avancés, formulés avec netteté ${ }^{97}$, et significatifs de cet intérêt éprouvé par les artistes pour un art mineur mais libre et plein de vie.

Le romantisme fantaisiste trouve ainsi dans le domaine de la décoration, de l'architecture et de la littérature du XVIII ${ }^{\mathrm{e}}$ siècle, l'expression de valeurs qu'il a reconnues pour siennes et qui le caractérisent aux yeux de la critique. Épris d'un art hostile aux règles du classicisme, se développant hors des sentiers battus et sans se proposer de but précis, un art qui se matérialise dans les raffinements d'un style ciselé et qui malmène ce que le bon sens appelle les convenances et le goût, nombre de Petits romantiques se montrent naturellement attirés par les formes contournées et souriantes du rococo, et par le style vivant et capricieux des récits dédaignés du XVIII ${ }^{\mathrm{e}}$ siècle. Le "joli", si significatif de la représentation que les romantiques se font de l'art au XVIII ${ }^{\mathrm{e}}$ siècle, plus reposant et plus mobile que le Beau, n'est plus unanimement méprisé : Janin se livre en 1832 à un éloge que ne renieraient pas Houssaye ou Gautier, et qui trouvera des échos dans l'œuvre des Goncourt ${ }^{98}$ :

Littérairement parlant, je pleure encore madame la marquise de Pompadour; elle a emporté dans sa tombe le secret du joli.

Le joli ! (...) Je ne sais quoi sans définition. Échos, parfums, rayons ! un faux brillant et un feu follet... il arrive, il entre, il se pose, il rit dans la glace, il s'assied à table avec vous, il chante, il minaude, il écrit de petits billets, il aime à la rage les opéras et les belles danseuses, il s'occupe en minaudant de petite musique et de petits vers, de petites intrigues, de tout ce qui est mignon, vif, léger, frivole ! Ah ! vive le joli ! C'est le joli qui a taillé les verres à facettes, inventé la poudre à poudrer, les mouches et les ballets ; il a fixé les amours aux plafonds, il a jeté son fard à la joue ; (...) Pauvre petit monstre ! il est parti avec M. Voisenon et M. Crébillon fils. Il est parti ; on croyait que le beau allait venir à sa place, il n'est pas venu, et nous autres, nous sommes restés par terre, entre le beau et le joli, à peu près comme l'art dramatique entre les deux théâtres français. ${ }^{99}$

\footnotetext{
${ }^{95}$ : «L'émotion, la verve, l'inspiration et tout ce qui y ressemble lui étaient choses complètement étrangères », note Sainte-Beuve. («Marivaux » (13 janvier 1854), Les Grands écrivains français, Paris, Garnier frères, 1930, p. 44). Surtout, la préciosité de son langage agace le critique : «il dépasse sans s'en douter la mesure, tombe ostensiblement dans le raffiné, et devient maniéré, minaudier, façonnier, le plus naturellement du monde » (Ibid., p. 54). Ainsi son «grand et perpétuel défaut (...) est de s'appesantir à satiété sur la même pensée, qui a presque toujours commencé par être juste et fine, et qu'il trouve moyen de fausser en la raffinant » (Ibid., p. 61).

96 Ibid., p. 55.

${ }^{97}$ Le critique rend justice à la profondeur, peu souvent soulignée, de sa pensée : « c'est un théoricien et un philosophe, beaucoup plus perçant qu'on ne croit sous sa mine coquette » (Ibid., p. 42). « Marivaux n'a pas seulement un talent fin et une rare fertilité d'idées qu'il rend avec imprévu, il a la théorie de son talent et sait le pourquoi de sa nouveauté », note encore Sainte-Beuve (Ibid., p. 40). Enfin, son théâtre est une réussite : «le théâtre de Marivaux est resté sa gloire. Ses cadres ne sont pas étendus, mais ils sont neufs, et il a été vraiment poète, il a créé quelque chose de ce côté » (Ibid., p. 70).

98 «Le joli, - voilà, à ces heures d'histoire légère, le signe et la séduction de la France. Le joli est l'essence et la formule de son génie. Le joli est le ton de ses mœurs. Le joli est l'école de ses modes. Le joli, c'est l'âme du temps - et c'est le génie de Boucher » (Les Goncourt, «Boucher», L'Art du XVIIIe siècle, Paris, Charpentier, 1881, t. I, p. 196).

99 J. Janin, Rosette, Contes fantastiques et contes littéraires (1832), Paris, Genève, Slatkine Reprints, 1979, p. 197.
} 
Il ne s'agit pas de hisser l'art du XVIII siècle à la hauteur du beau antique. Le joli, le rococo, le Pompadour, provoquent toujours sourires et regards ironiques, et ne se confondent pas avec l'art véritable. Loin de vouloir opérer un tel rapprochement, les écrivains leur sont au contraire reconnaissants d'avoir su exister hors de la norme, et pour eux-mêmes. Qu'ils s'étonnent du charme puissant de ses formes, où qu'ils expliquent sa séduction par des théories sur l'arabesque, le zigzag ou la vie, c'est son statut d'art secondaire qui, selon les jeunes romantiques, procure au rococo un avantage considérable sur toute forme d'esthétique figée par les conventions. La vision qui nous est donnée de l'esthétique du passé se montre ainsi étonnamment révélatrice des nouvelles orientations de la littérature à l'époque envisagée : le passage d'une représentation extrêmement négative de l'art du XVIII ${ }^{\mathrm{e}}$ siècle à un vif intérêt manifesté à l'égard du rococo traduit dans ses nuances l'évolution d'un romantisme peut-être trop sérieux, conventionnel à nos yeux, vers une esthétique privilégiant la liberté, l'irrégularité et le caprice. Il met également l'accent sur un contexte socio-politique déterminant dans l'histoire littéraire du $\mathrm{XIX}^{\mathrm{e}}$ siècle. L'option d'une esthétique du caprice, adoptée dans les années 1830, peut être interprétée comme une forme de réponse à la désillusion des jeunes romantiques, une manière, pour ces artistes "désenchantés", de se dégager de la masse par une marginalisation tant comportementale que littéraire. Et l'on comprend comment le goût pour le rococo, cet art si généralement décrié avant la monarchie de Juillet, et issu d'un temps dont les premiers romantiques dans leur majorité ne parlaient qu'avec mépris, puisse aussi apparaître comme une arme chargée d'enjeux idéologiques dans cette quête de l'originalité à tout prix, dans ce désir d'une différence et d'une distance toutes aristocratiques. 